\title{
A Retrospective Descriptive Study on Distribution of Primary Squamous Cell Carcinoma in Different Sites of Oral Cavity in a Tertiary Care Centre, Chennai
}

\author{
Bakyalakshmi K , Sarala K², Karthikeyan D ${ }^{3}$, Kayal L ${ }^{4}$ \\ ${ }^{1}$ Department of Dental Surgery, Government Stanley Medical College and Hospital, Chennai, Tamilnadu, India. ${ }^{2}$ Department \\ of Dental Surgery, Government Medical College and Hospital, Omandurar Government Estate, Chennai, Tamilnadu, India. \\ ${ }^{3}$ Department of Dental Surgery, Government Stanley Medical College and Hospital, Chennai, Tamilnadu, India. ${ }^{4}$ Department \\ of Dental Surgery, Government Stanley Medical College and Hospital, Chennai, Tamilnadu, India.
}

\section{ABSTRACT}

\section{BACKGROUND}

Oral cancer is one of the most common cancers in the world. In India it is the most common cancer among the males; among the females, it is the third most common cancer. The purpose of this study is to retrospectively evaluate the different primary site of occurrence of Oral Squamous Cell Carcinoma (OSCC), its age and gender distribution.

\section{METHODS}

A retrospective descriptive study was conducted in the department of Dental Surgery, Stanley Medical College and Hospital. A total number of 196 patients with histologically confirmed diagnosis of OSCC were selected for the study. The cases were systematically grouped under various sites of OSCC, age and gender and the findings were formulated.

\section{RESULTS}

A total number of 196 patients were diagnosed as OSCC with the male to female ratio of $3: 1$, buccal mucosa $78(39.79 \%)$ and tongue $77(39.28 \%)$ are the most common sites involved, followed by mandibular alveolus with 13 (6.63\%). 7 $(3.57 \%)$ had primary lesion at maxillary and retromolar trigone respectively. 5 $(2.51 \%)$ had the lesion in palate and floor of the mouth. Four patients $(2.04 \%)$ had the lesion in labial mucosa. Highest number of 57 (29.8\%) patients was in the age group of 41-50.

\section{CONCLUSIONS}

Oral cancer is one of the major public health problems associated with risk habits commonly involving the buccal mucosa and tongue. It can easily be prevented by conducting awareness programme among the high-risk groups. Prevention and early intervention will reduce the mortality rate of OSCC.

\section{KEY WORDS}

Oral Squamous Cell Carcinoma, Primary Site, Buccal Mucosa, Tongue
Corresponding Author:

Dr. Sarala Kessavalou,

Department of Dental Surgery,

Government Medical College and Hospital, Omandurar Government Estate, Chennai,

Tamilnadu, India.

E-mail:drk.sarala@gmail.com

DOI: $10.14260 /$ jemds/2019/745

Financial or Other Competing Interests: None.

How to Cite This Article:

Bakyalakshmi K, Sarala K, Karthikeyan D, et al. A retrospective descriptive study on distribution of primary squamous cell carcinoma in different sites of oral cavity in a tertiary care centre, Chennai. J. Evolution Med. Dent. Sci. 2019;8(46): 3437-3440, DOI: 10.14260/jemds/2019/745

Submission 06-06-2019, Peer Review 01-11-2019,

Acceptance 08-11-2019,

Published 18-11-2019. 


\section{BACKGROUND}

Oral squamous cell carcinoma (OSCC) represents $95 \%$ of all forms of head and neck cancer, and during the past decade its incidence has increased by $50 \% .^{1}$ Globally Oral Squamous Cell Carcinoma (OSCC) is the eighth more common cancer. ${ }^{2}$ Consumption of tobacco is one of the most important risk factors for the development of OSCC. Cigarette and cigar smoking, tobacco chewing, using snuff accounts for the development of OSCC. 85\% of head and neck cancers are due to use of tobacco. ${ }^{3}$ Apart from tobacco, alcohol consumption, dietary factors, human papilloma virus (HPV) infection, genetic factors and oral hygiene are other risk factors. ${ }^{4}$ OSCC has a most common clinical feature of ulcerated lesion with a central necrotic area or raised exophytic margins. ${ }^{5}$ It may also present as a lump, as a red lesion, as a white or mixed white and red lesion, as a non-healing extraction socket or as a cervical lymph node enlargement, characterized by hardness or fixation. OSCC occurs commonly on the buccal mucosa, tongue, floor of the mouth, palate, alveolus and lip. OSCC can be prevented and detected at an early stage. The purpose of the retrospective descriptive study was to evaluate the common site of occurrence of OSCC in a tertiary care hospital in Chennai.

\section{METHODS}

In this retrospective descriptive study (January 2016 to December 2018), data of 196 patients with histologically confirmed diagnosis of OSCC were selected from the department of Dental Surgery, Stanley Medical College and Hospital. Details of patient's age, gender and site of primary tumour were collected and statistically analysed and the results were formulated. The anatomic sites included in the study were buccal mucosa, mandibular alveolus, maxillary alveolus, tongue, palate, retro molar trigone, floor of the mouth and labial mucosa.

\section{RESULTS}

Total numbers of 196 patients were included in the study. Among the 196 patients 147 (75\%) were males and 49 (25\%) were females with a male: female ratio of $3: 1$ (Table 1), the age of the patient ranged from 28 years to 80 years. Table 2 shows the age of distribution of the patients. Maximum numbers of $57(29.8 \%)$ patients were under the age group of 41-50 years, followed by $48(24.4 \%)$ patients in the age group of 31-40 years. Minimum number of 5 (2.5\%) were in the age group of $21-30$ years. $45(22.9 \%)$ were in the age group of 51-60 years and 39 (19.89\%) above 60 years of age. Various site of occurrence of OSCC is shown in Table 3. Among the site of occurrence of OSCC buccal mucosa and tongue are the most common sites involved in this study with $78(39.79 \%)$ and 77 (39.28\%) of patients respectively. 13 (6.63\%) patients had OSCC of mandibular alveolus. 7 (3.57\%) cases had OSCC of maxillary alveolus and retromolar trigone respectively. Followed by $5(2.51 \%)$ cases each involving the palate and floor of the mouth and $4(2.04 \%)$ cases with the involvement of labial mucosa.
Table 4 shows the variation in distribution of squamous cell carcinoma involving the various sites of oral cavity such as buccal mucosa, tongue, mandibular alveolus, maxillary alveolus, retro molar trigone, palate, floor of the mouth and labial mucosa according to age group and gender. Out of the total 196 patients 78 (39.79\%) had OSCC of buccal mucosa. Among the 78 patients 57 (73.07\%) were males and 21 (26.92\%) were females. Maximum number of patients 29 $(37.17 \%)$ in both the gender were in the age group of $41-50$ and minimum in the age group if $21-30$ with only $3(3.84 \%)$ male patients. Total of 77 (39.28\%) had tongue involvement out of which $60(77.92 \%)$ were males and 17(22.07\%) were females. $19(24.67 \%)$ of males were in the age group of 31-40 and $15(19.48 \%)$ and $14(18.18 \%)$ male patients were in the age group of 41-50 and 51-60 respectively. Only 1 (1.29\%) case had the involvement of tongue in the age group of 21-30 among both the sexes. Total of $13(6.63 \%)$ cases had OSCC in the mandibular alveolus with $8(61.53 \%)$ males and 5 $(38.46 \%)$ females. Maximum of $6(46.15 \%)$ were in the age group of $41-50$ with $4(30.76 \%)$ males and $2(15.25 \%)$ females. $4(30.76 \%)$ were in the age group of $41-50$ with 2 $(15.38 \%)$ of cases in each gender. One $(7.69 \%)$ male patient was in the age group of more than 60 years and no cases reported in the age group of 21-30. The variation in the involvement of maxillary alveolus is, among 196 patients 7 $(3.57 \%)$ were in this group. $4(57.14 \%)$ were female and 3 $(42.85 \%)$ were males. Maximum of $3(42.85 \%)$ cases were in the age group of more than 60 followed by 2 (28.57\%) in the age group of 51-60 and one female in the age group of 31-40 and 41-50 respectively. All the $5(2.51 \%)$ cases reported in the palate were males, with $2(40 \%)$ cases in the age group of 31-40 and 51-60 respectively. One (20\%) male patient was above the age group of 60 . No female patient had palatal involvement. Similar to the distribution of palate there were no female patients with OSCC in floor of the mouth. Among the total number of $5(2.51 \%)$ male patients $2(40 \%), 2(40 \%)$ and $1(20 \%)$ were in the age group of 31-40, 51-61 and above 60 years respectively. Only $4(2.04 \%)$ had OSCC in labial mucosa in this study. Out of the total number of 49 female patients only one $(25 \%)$ above the age of 60 years had the lesion in labial mucosa. Among the males $2(50 \%)$ patients were above the age of 60 and $1(25 \%)$ was in the age group of $31-40$ with total number of $3(75 \%)$ male patients.

\begin{tabular}{|c|c|c|}
\hline Gender & No. of Cases (n=196) & \% of Patients \\
\hline Male & 147 & $75 \%$ \\
\hline Female & 49 & $25 \%$ \\
\hline \multicolumn{2}{|c|}{ Table 1. Prevalence of OSCC According to Gender } \\
\hline
\end{tabular}

\begin{tabular}{|c|c|c|}
\hline Age of Patients in (Years) & No. of Patients (n=196) & \% of Patients \\
\hline $21-30$ & 5 & 2.5 \\
\hline $31-40$ & 48 & 24.4 \\
\hline $41-50$ & 57 & 29.8 \\
\hline $51-60$ & 45 & 22.9 \\
\hline$>60$ & 39 & 19.89 \\
\hline \multicolumn{2}{|c|}{ Table 2. Prevalence of OSCC in Different Age Groups } \\
\hline
\end{tabular}

\begin{tabular}{|c|c|c|}
\hline Different Site of Oral Cavity & No. of Patients (n=196) & \% of Patients \\
\hline Buccal mucosa & 78 & 39.79 \\
\hline Tongue & 77 & 39.28 \\
\hline Mandibular alveolus & 13 & 6.63 \\
\hline Maxillary alveolus & 7 & 3.57 \\
\hline Retro molar trigone & 7 & 3.57 \\
\hline Palate & 5 & 2.51 \\
\hline Floor of the mouth & 5 & 2.51 \\
\hline Labial mucosa & 4 & 2.04 \\
\hline \multicolumn{2}{|c|}{ Table 3. Distribution of OSCC in Various Sites of Oral Cavity } \\
\hline
\end{tabular}




\begin{tabular}{|c|c|c|c|c|c|c|c|c|c|c|}
\hline \multirow[b]{3}{*}{ Site } & \multicolumn{10}{|c|}{ Age (Years) } \\
\hline & \multicolumn{2}{|c|}{ 21-30 } & \multicolumn{2}{|c|}{$31-40$} & \multicolumn{2}{|c|}{ 41-50 } & \multicolumn{2}{|c|}{ 51-60 } & \multicolumn{2}{|c|}{$>60$} \\
\hline & $\begin{array}{l}\underset{a}{a} \\
= \\
\frac{0}{0} \\
\sum\end{array}$ & 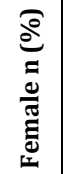 & 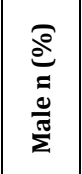 & 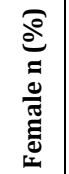 & $\underbrace{\underset{0}{0}}_{\substack{0 \\
0}}$ & 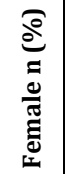 & 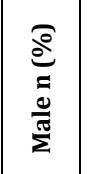 & 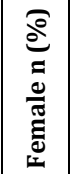 & 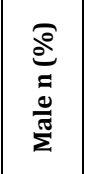 & 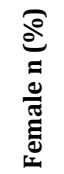 \\
\hline $\begin{array}{l}\text { Buccal } \\
\text { mucosa }\end{array}$ & \begin{tabular}{|c|}
3 \\
$(3.8)$ \\
\end{tabular} & - & $\begin{array}{c}17 \\
(21.79) \\
\end{array}$ & \begin{tabular}{|c|}
3 \\
$(3.8)$ \\
\end{tabular} & \begin{tabular}{|c|}
22 \\
$(28.2)$ \\
\end{tabular} & \begin{tabular}{|c|}
7 \\
$(8.97)$ \\
\end{tabular} & $\begin{array}{c}10 \\
(12.82)\end{array}$ & $\begin{array}{c}4 \\
(5.12) \\
\end{array}$ & $\begin{array}{c}5 \\
(6.41) \\
\end{array}$ & \begin{tabular}{|c|}
7 \\
$(8.91)$ \\
\end{tabular} \\
\hline Tongue & \begin{tabular}{c|}
1 \\
$(1.29)$ \\
\end{tabular} & $\begin{array}{c}1 \\
(1.29) \\
\end{array}$ & $\begin{array}{c}19 \\
(24.67)\end{array}$ & $\begin{array}{c}2 \\
(2.59) \\
\end{array}$ & $\begin{array}{c}15 \\
(19.48)\end{array}$ & \begin{tabular}{|c|}
7 \\
$(9.09)$ \\
\end{tabular} & $\begin{array}{c}14 \\
(18.18) \\
\end{array}$ & \begin{tabular}{|c|}
3 \\
$(3.8)$
\end{tabular} & $\begin{array}{c}12 \\
(15.58) \\
\end{array}$ & \begin{tabular}{|c|}
4 \\
$(5.1)$ \\
\end{tabular} \\
\hline $\begin{array}{c}\text { Mandibular } \\
\text { alveolus }\end{array}$ & - & - & $\begin{array}{c}1 \\
(7.69)\end{array}$ & $\begin{array}{c}1 \\
(7.69) \\
\end{array}$ & $\begin{array}{c}4 \\
(30.76)\end{array}$ & $\begin{array}{c}2 \\
(15.2) \\
\end{array}$ & $\begin{array}{c}2 \\
(15.2)\end{array}$ & $\begin{array}{c}2 \\
(15.2) \\
\end{array}$ & $\begin{array}{c}1 \\
(7.69)\end{array}$ & $\begin{array}{c}1 \\
(7.69) \\
\end{array}$ \\
\hline \begin{tabular}{|c|} 
Maxillary \\
alveolus
\end{tabular} & - & - & - & $\begin{array}{c}1 \\
(14.2) \\
\end{array}$ & $\begin{array}{c}1 \\
(14.2) \\
\end{array}$ & $\begin{array}{c}1 \\
(14.2) \\
\end{array}$ & $\begin{array}{c}1 \\
(14.2)\end{array}$ & $\begin{array}{c}1 \\
(14.2) \\
\end{array}$ & $\begin{array}{c}2 \\
(28.5 \%) \\
\end{array}$ & $\begin{array}{c}1 \\
(14.2) \\
\end{array}$ \\
\hline $\begin{array}{l}\text { Retro } \\
\text { molar } \\
\text { trigone }\end{array}$ & - & - & $\mid \begin{array}{c}2 \\
(28.57)\end{array}$ & - & $\mid \begin{array}{c}2 \\
(28.57)\end{array}$ & - & $\mid \begin{array}{c}2 \\
(28.57)\end{array}$ & - & - & - \\
\hline Palate & - & - & $2(40)$ & - & $2(40)$ & - & $1(20)$ & - & - & - \\
\hline \begin{tabular}{|c|} 
Floor of the \\
mouth
\end{tabular} & - & - & $2(40)$ & - & - & - & $2(40)$ & - & $1(20)$ & - \\
\hline \begin{tabular}{|c|} 
Labial \\
mucosa \\
\end{tabular} & - & - & $1(25)$ & - & - & - & - & - & $2(50)$ & $1(25)$ \\
\hline $\begin{array}{r}\text { Table } 4 . \\
\text { Var }\end{array}$ & 年 & in 1 & DIS & S & of उqu & mou & 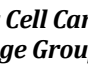 & . & 4 & 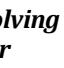 \\
\hline
\end{tabular}

\section{DISCUSSION}

The aim of this study was to represent variation in distribution pattern of OSCC in the oral cavity according to age group and gender. Oral cancer is the major public health problem of India. It is one among the top three types cancer in Indian subcontinent. ${ }^{6}$ The most common oral malignancy representing up to $80-90 \%$ of all malignant neoplasm of oral cavity is OSCC. Major risk factors of OSCC include smoking, drinking, human papilloma viral infection (HPV), candida infection, genetic predisposition and UV radiation exposure. ${ }^{7}$ OSCC predominantly affects males with variables of male: female ratio ranging from $6: 1$ to $2: 1,8,9$ in accordance with the present study where the ratio is $3: 1$. The age range of the patient in the present study was 28 to 80 years. Peak prevalence of OSCC (29.8\%) was observed in the age group of 41 to 50 this was in consistent with Chettri DK et al,10 Singh MP et al. ${ }^{11}$

In the present study buccal mucosa was the most common site of occurrence of OSCC (39.79\%), it was in consistent with Johnson NW et al, Srivastava V et al. ${ }^{12}$ In southeast Asian countries buccal mucosa is the most common site for OSCC, this is mainly because of the use of smokeless tobacco products like gutkha, betelnut chewing with or without tobacco products. Consumption of these products results in premalignant disorders like oral sub mucous fibrosis resulting in increased incidence of OSCC of buccal mucosa. ${ }^{13}$

Albuquerque et al, ${ }^{14}$ Falaki et $\mathrm{al}^{15}$ stated that tongue is the most common site of occurrence of OSCC this was in consistent with our study (39.28\%). In Western countries OSCC is common in the tongue and the floor of the mouth due to alcohol consumption and smoking. ${ }^{16}$ In the present study alveolus is the third most common site of involvement of OSCC $(10.22 \%)$. Lesion involving the mandibular alveolus is mostly by direct extension. Prevalence of mandibular lesion ranges from 12 to $56 \% .{ }^{17}$ The retromolar trigone (RMT) is a triangular area bounded by temporal crest on the medial side, anterior border of ramus on the lateral side, and base posterior to the socket for the third molar. ${ }^{18}$ In the present study 7 (3.57\%) had OSCC of RMT with a male predominance of 6 cases. Male predominance was observed in Tandon et $\mathrm{al}^{19}$ with $6.67 \%$ of RMT. Tumours involving RMT can extend to involve muscles of mastication, soft palate, tonsillar pillars, floor of mouth, and parapharyngeal space. OSCC of palate is common among male due to the habit of smoking. In the present study $5(2.51 \%)$ patients had OSCC of palate and all the 5 were males. This was in accordance with the study of Lihera et al 2008 20, in which the Chinese reported the highest M: F ratio of 3:1. In accordance with Shenoi et al ${ }^{21}$ and Tandon $\mathrm{P}$ et $\mathrm{al}^{22}$ OSCC of floor of the mouth was $2.51 \%$ and $2.35 \%$ respectively with male predominance this was in accordance with the present study. In our study $2.03 \%$ had OSCC of floor of the mouth all were male patients. In the study of Tandon et al $1.33 \%$ had oral cancer of labial mucosa, in the present study it was $2.04 \%$.

\section{CONCLUSIONS}

OSCC is more common among males of $41-50$ years of age. Buccal mucosa and the tongue are the common sites of involvement of OSCC followed by the alveolar region. OSCC of RMT, palate, floor of the mouth and labial mucosa are common among males. Oral cavity is accessible for visual examination and can be diagnosed earlier by self-mouth examination. Awareness should be increased among the highrisk groups. Preventive measures have to be taken to reduce the incidence and mortality rate of oral cancer.

\section{REFERENCES}

[1] Bray F, Sankila R, Ferlay J, et al. Estimates of cancer incidence and mortality in Europe in 1995. Eur J Cancer 2002;38(1):99-166.

[2] Corso GD, Villa A, Tarsitano A, et al. Current trends in oral cancer: a review. Cancer Cell Microenviron 2016;3:1-11.

[3] Gandini S, Botteri E, Iodice S, et al. Tobacco smoking and cancer: a meta-analysis. Int J Cancer 2008;122(1):15564.

[4] Dikshit R, Gupta PC, Ramasundaraheettige C, et al. Cancer mortality in India: a nationally representative survey. Lancet 2012;379(9828):1807-16.

[5] Pires FR, Ramos AB, Oliveira JB, et al. Oral squamous cell carcinoma: clinicopathological features from 346 cases from a single oral pathology service during an 8-year period. J Appl Oral Sci 2013;21(5):460-7.

[6] Sankaranarayanan R, Ramadas K, Thomas G, et al. Effect of screening on oral cancer mortality in Kerala, India: a cluster-randomised controlled trial. Lancet 2005;365(9475):1927-33.

[7] Johnson NW, Jayasekara P, Amarasinghe AA. Squamous cell carcinoma and precursor lesions of the oral cavity: epidemiology and etiology. Periodontol 2000 2011;57(1):19-37. 
[8] Al-Rawi NH, Talabani NG. Squamous cell carcinoma of the oral cavity: a case series analysis of clinical presentation and histological grading of 1425 cases from Iraq. Clin Oral Invest 2008;12(1):15-8.

[9] Bakyalakshmi K, Karthikeyan D. Clinico-epidemiological study of oral squamous cell carcinoma- a retrospective study in a tertiary care centre in Chennai. J Evolution Med Dent Sci 2018;7(07):816-9.

[10] Chhetri DK, Rawnsley JD, Calcaterra TC. Carcinoma of the buccal mucosa. Otolaryngol Head Neck Surg 2000;123(5):566-71.

[11] Singh MP, Kumar V, Agarwal A, et al. Clinicoepidemiological study of oral squamous cell carcinoma: a tertiary care centre study in North India. J Oral Biol Craniofac Res 2016;6(1):31-4.

[12] Srivastava V, Kaur T, Sucharita V. Consences document for management of buccal mucosa cancer. New Delhi: Indian Council of Medical Research, 2014.

[13] Agrawal M, Pandey S, Jain S, et al. Oral cancer awareness of the general public in Gorakhpur city, India. Asian Pac J Cancer Prev 2012;13(10):5195-9.

[14] Albuquerque R, López-López J, Marí-Roig A, et al. Oral Tongue Squamous Cell Carcinoma (OTSCC): alcohol and tobacco consumption versus non-consumption. a study in a Portuguese population. Braz Dent J 2011;22(6):51721.

[15] Falaki F, Dalirsani Z, Pakfetrat A, et al. Clinical and histopathological analysis of oral squamous cell carcinoma of young patients in Mashhad, Iran: a retrospective study and review of literatures. Med Oral Patol Oral Cir Bucal 2011;16(4):e473-7.
[16] Muller S, Pan Y, Li R, et al. Changing trends in oral squamous cell carcinoma with particular reference to young patient: 1971-2006. The Emory University experience. Head Neck Pathol 2008;2(2):60-6.

[17] Bahadur S. Mandibular involvement in oral cancer. J Laryngeal Otol 1990;104(12):968-71.

[18] McGregor I, McGregor F. Cancer of the face and mouth: pathology and management for surgeons. Edinburgh: Churchill Livingstone 1986: p. 499-510.

[19] Tandon A, Bordoloi B, Jaiswal R, et al. Demographic and clinicopathological profile of oral squamous cell carcinoma patients of North India: a retrospective institutional study. SRM J Res Dent Sci 2018;9(3):114-8.

[20] Liu L, Kumar SK, Sedghizadeh PP, et al. Oral squamous cell carcinoma incidence by subsite among diverse racial and ethnic populations in California. Oral Surg Oral Med Oral Pathol Oral Radiol Endod 2008;105(4):470-80.

[21] Shenoi R, Devrukhkar V, Chaudhuri, et al. Demographic and clinical profile of oral squamous cell carcinoma patients: a retrospective study. Indian J Cancer 2012;49(1):21-6.

[22] Tandon P, Dadhich A, Saluja H, et al. The prevalence of squamous cell carcinoma in different sites of oral cavity at our Rural Health Care Centre in Loni, Maharashtra - a retrospective 10-year study. Contemporary Oncology (Poznan, Poland) 2017;21(2):178-83. 